\title{
Unidirectional valved patch closure of ventricular septal defects with severe pulmonary arterial hypertension: Hemodynamic outcomes
}

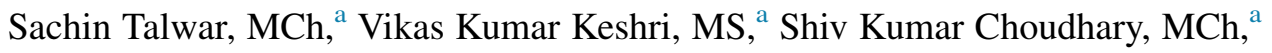 \\ Saurabh Kumar Gupta, DM, ${ }^{a}$ Sivasubramanian Ramakrishnan, DM, ${ }^{\mathrm{a}}$ Anita Saxena, DM, ${ }^{\mathrm{a}}$ \\ Shyam Sunder Kothari, DM, ${ }^{\mathrm{a}}$ Rajnish Juneja, DM, ${ }^{\mathrm{a}}$ Guresh Kumar, $\mathrm{PhD},{ }^{\mathrm{b}}$ and Balram Airan, $\mathrm{MCh}^{\mathrm{a}}$
}

\begin{abstract}
Objective: The purpose of the present study was to study the midterm hemodynamic outcomes of unidirectional valved patch closure of ventricular septal defects (VSDs) in patients with VSD and pulmonary arterial hypertension $(\mathrm{PAH})$.
\end{abstract}

\begin{abstract}
Methods: From January 2006 to January 2012, 20 patients with VSD with PAH and a pulmonary vascular resistance index $>8$ Wood units underwent VSD closure with a unidirectional valved patch using the technique previously described by us. Of these, 13 patients agreed to follow-up cardiac catheterization and were studied at a mean follow-up of $34.7 \pm 18.6$ months (range, 2-56). The mean age of these 13 patients was $8.5 \pm 4.4$ years (range, 2-19; median, 9), and the mean preoperative systemic saturation was 94.1\% $\pm 3.4 \%$ (range, 87-99; median, 95.0) The mean preoperative pulmonary artery systolic pressure was $96.2 \pm 13.6 \mathrm{~mm} \mathrm{Hg}$ (range, 75-115; median, 103.0), and the mean preoperative pulmonary vascular resistance index was $10.0 \pm 2.1$ Wood units (range, 8.0-15.1; median, 9.3).
\end{abstract}

Results: At follow-up cardiac catheterization, the mean systemic saturation had increased to $98.92 \%$. The pulmonary vascular resistance index had decreased significantly to $5.8 \pm 2.1$ Wood units $(P=.02)$. A significant decrease was seen in the pulmonary artery systolic, diastolic, and mean pressures $(P=.000)$, and none of the patients had severe PAH. No patients died, and all patients were in New York Heart Association class I.

Conclusions: Unidirectional valved patch closure of VSD is a promising technique for patients with a large VSD and severe PAH. It had a favorable effect on the immediate, early, and midterm clinical outcomes and hemodynamic parameters. (J Thorac Cardiovasc Surg 2014;148:2570-5)

It is not uncommon in third world countries to encounter a patient with a ventricular septal defect (VSD) with severe pulmonary arterial hypertension (PAH). The treatment of these patients has been fraught with the early and midterm adverse effects of longstanding PAH. ${ }^{1,2}$ Unidirectional valved patch (UVP) closure of the VSD has been described as one of the surgical alternatives for such patients to reduce the early morbidity and mortality and to possibly prevent right ventricular decompensation in the mid term. ${ }^{3-8}$ In our earlier publications, we described our own method of VSD closure using a UVP ${ }^{5}$ and its early and midterm results. ${ }^{9}$ We now present the detailed hemodynamic characteristics and cardiac catheterization data from these patients as objective evidence of the success of this technique.

From the Cardiothoracic Centre ${ }^{\mathrm{a}}$ and Department of Biostatistics, ${ }^{\mathrm{b}}$ All India Institute of Medical Sciences, New Delhi, India.

Disclosures: Authors have nothing to disclose with regard to commercial support.

Received for publication Feb 27, 2013; revisions received Sept 13, 2013; accepted for publication Oct 29, 2013; available ahead of print Dec 11, 2013.

Address for reprints: Sachin Talwar, MCh, Department of Cardiothoracic and

Vascular Surgery, All India Institute of Medical Sciences, New Delhi 110029, India

(E-mail: sachintalwar@hotmail.com).

$0022-5223 / \$ 36.00$

Copyright (c) 2014 by The American Association for Thoracic Surgery

http://dx.doi.org/10.1016/j.jtcvs.2013.10.052

\section{METHODS}

From January 2006 to January 2012, 20 patients with VSD and a basal pulmonary vascular resistance (PVR) index (PVRI) of $>8$ Wood units underwent VSD closure with a UVP using the technique previously described by Choudhary and colleagues. ${ }^{5}$ The medical records of these patients were analyzed and the preoperative characteristics recorded (Table 1). All 20 patients were contacted and cardiac catheterization was recommended to document the hemodynamic and oximetry data. Of the 20 patients, 13 agreed to undergo cardiac catheterization. The institutional ethics committee approved study protocol.

Of the 20 patients for whom preoperative and early results were available, 12 were male. The mean patient age was $9.4 \pm 5.5$ years (range, 223; median, 8). Of the 20 patients, 18 were in New York Heart Association class III at surgery. None of the patients had cyanosis. The preoperative radiograph showed mild cardiomegaly in 7 patients and no cardiomegaly in 13 patients, with signs of severe PAH. A bidirectional shunt with a predominant left to right shunt was seen on the echocardiogram in 18 patients and 2 patients had a right to left shunt across the VSD. A total of 18 patients had a perimembranous VSD; 1 of these 18 had an inlet extension of the VSD. One patient had a muscular VSD and a perimembranous VSD, and one had 2 muscular VSDs. Four patients had a concurrent atrial septal defect and four had a patent ductus arteriosus. These were repaired simultaneously.

\section{Cardiac Catheterization Protocol}

The protocol for cardiac catheterization and hemodynamic and oximetry data collection was uniform. It consisted of adequate conscious sedation and analgesia. Right heart catheterization was performed using Swan-Ganz balloon-tipped catheter, and left heart catheterization was performed using a pigtail catheter. The pressures were recorded at the chambers, and samples were collected from the superior vena cava, pulmonary artery, left ventricle, 


\author{
Abbreviations and Acronyms \\ ICU = intensive care unit \\ $\mathrm{PAH}=$ pulmonary arterial hypertension \\ PAP = pulmonary artery pressure \\ PVR = pulmonary vascular resistance \\ PVRI $=$ pulmonary vascular resistance index \\ $\mathrm{Qp}=$ pulmonary blood flow \\ Qs $=$ systemic blood flow \\ $\mathrm{UVP}=$ unidirectional valved patch \\ VSD $=$ ventricular septal defect
}

and aorta. In all patients, high-flow, $100 \%$ oxygen was administered using a face mask for 10 minutes, and samples were again obtained from the same sites. Oxygen consumption was calculated as the assumed oxygen consumption according to the age, gender, and heart rate of the patient from the standard normograms. Oximetry and blood gas analysis of the samples was performed, and, using the Fick principle, the baseline values of the pulmonary blood flow (Qp), systemic blood flow (Qs), PVRI, and indexed systemic vascular resistance were calculated using standard equations. These indexes were also calculated after oxygen administration, taking into account the correction required for dissolved oxygen. The data were recorded and interpreted, taking into consideration the clinical status of the patients.

The mean basal preoperative arterial saturation was $94.1 \% \pm 2.9 \%$ (range, $87 \%-99 \%$; median, $94.0 \%$ ), which increased to a mean of $98.7 \% \pm 1.1 \%$ (range, $97 \%-100 \%$; median, $99.0 \%$ ) after the administration of high-flow oxygen for 10 minutes. The mean preoperative pulmonary artery systolic pressure was $96.4 \pm 11.9 \mathrm{~mm} \mathrm{Hg}$ (range, 75-115; median, 100 ), and the mean pulmonary artery diastolic pressure was $46.4 \pm 11.7$ $\mathrm{mm} \mathrm{Hg}$ (range, 23-67; median, 45.5). On administration of oxygen, the pulmonary artery systolic pressure and pulmonary artery diastolic pressure decreased to $68.2 \pm 25.9 \mathrm{~mm} \mathrm{Hg}$ and $28.8 \pm 12.6 \mathrm{~mm} \mathrm{Hg}$, respectively. The mean/Qs ratio was $1.5 \pm 0.5$ (range, 1.1-3.2; median, 1.40) and increased to $4.0 \pm 0.9$ (range, 2.8-6.5) with oxygen administration. The mean basal PVRI for the 20 patients was $10.9 \pm 2.3$ Wood units (range, 8.0-16.1; median, 10.05). All patients showed a decrease in the PRVI with oxygen administration, with a concomitant increase in left to right shunting. The mean PVRI after oxygen administration was $3.78 \pm 1.95$ Wood units (range, 1.3-9.8; median, 4.20).

\section{Decision Making}

The decision to perform surgery was determined by the referring cardiologist and operating surgeon and acceptance of the surgical risks by the patient and family, with their informed consent. No absolute value of PVRI was taken as a cutoff. A combination of clinical findings (ie, age, cardiomegaly, flow murmurs), chest radiographic findings (ie, cardiomegaly, pulmonary plethora), and electrocardiographic findings (ie, left ventricular volume overload and hypertrophy) were used, along with the hemodynamic data and response to the 10 minutes of oxygen inhalation, to determine the patient's operability. As is apparent from the preoperative data of our patients, a patient with a PVRI as great as 16 underwent surgery. None of these children had cyanosis clinically, although no exercise test was performed before cardiac catheterization. We did not consider systemic desaturation in the basal state at cardiac catheterization alone to be indicative of operability, because it could have resulted from extra sedation in some cases and would have normalized with oxygen inhalation.

\section{Management}

VSD closure was performed using previously reported techniques. ${ }^{5,9}$ The interatrial septum was always completely closed in these patients, because a valved communication had been provided at the level of the VSD. As detailed in our previous reports, ${ }^{5,9}$ phenoxybenzamine $(1 \mathrm{mg} / \mathrm{kg})$ was administered at aortic cannulation and was continued postoperatively (1 $\mathrm{mg} / \mathrm{kg}$ every 8 hours). All patients received dopamine 5 to $10 \mu \mathrm{g} / \mathrm{kg} / \mathrm{min}$, nitroglycerin or nitroprusside 0.5 to $2 \mu \mathrm{g} / \mathrm{kg} / \mathrm{min}$, or milrinone before weaning from cardiopulmonary bypass. In the last 10 patients, sildenafil $0.5 \mathrm{mg} / \mathrm{kg}$ through the nasogastric tube was started after arrival in the intensive care unit (ICU). Early extubation was encouraged. After extubation, oral angiotensin-converting enzyme inhibitors or oral phenoxybenzamine and sildenafil were administered, and the inotropes were weaned off. The former were continued during the follow-up period indefinitely, because the optimal therapy duration for these patients is unknown.

\section{Statistical Analysis}

Statistical analysis was performed using the Statistical Package for Social Sciences, version 15.0 (SPSS, Inc, Chicago, Ill). Nominal variables are presented as frequencies and percentages. Parametric data are presented as the mean \pm standard deviation. Two levels in the same group were tested using a paired $t$ test, and intergroup analysis was performed using the independent Student $t$ test.

\section{RESULTS}

\section{Immediate Postoperative Course}

The immediate postoperative course has been previously described in detail. ${ }^{9}$ In brief, the mean systemic saturation at termination of cardiopulmonary bypass was $93.3 \% \pm$ 4.3\% (range, 84\%-100\%; median, 93\%). Three patients (patients 2,13, and 15; Table 1) had a right to left shunt intraoperatively on the transesophageal echocardiogram and had had episodes of systemic desaturation after termination of cardiopulmonary bypass and in the ICU. None of the patients required nitric oxide or extracorporeal membrane oxygenation support. No early deaths occurred. The mean duration of mechanical ventilation was only $7.6 \pm 2.7$ hours (range, 5-16; median, 7). The mean systemic saturation in the ICU was $96.3 \% \pm 4 \%$ (range, $87 \%-100 \%$; median, $98 \%$ ). The same 3 patients had episodes of systemic desaturation in the ICU, with the lowest saturation $87 \%$. These were documented as being due to a right to left shunt through the UVP on the transthoracic echocardiogram and were managed by supplemental oxygen without requiring the reinstitution of mechanical ventilation. The inotropes were weaned off on the first postoperative day in all patients. The mean ICU stay was $1.9 \pm 0.3$ days (range, $1-3$; median, 2). The mean hospital stay was $5.1 \pm 1.3$ days (median, 5 ; range, $4-10$ ).

\section{Follow-up Data}

The mean follow-up was $33 \pm 16.8$ months (range, 2-56; median, 36.5). At the last follow-up visit, all 20 patients were in New York Heart Association class I functional status, and none of the patients had cyanosis. The clinical cardiac examination findings were unremarkable.

\section{Chest Radiographic, Electrocardiographic, and Echocardiographic Features}

The chest radiography of 1 patient (patient 6) showed mild cardiomegaly of the right ventricular type; all other patients had a normal cardiac silhouette. 
TABLE 1. Preoperative characteristics of all 20 patients

\begin{tabular}{|c|c|c|c|c|c|c|c|c|c|c|c|c|c|c|c|c|}
\hline \multirow[b]{2}{*}{ Pt. No. } & \multirow[b]{2}{*}{ Age (y) } & \multirow[b]{2}{*}{ Gender } & \multicolumn{2}{|c|}{$\mathrm{SpO}_{2}(\%)$} & \multicolumn{2}{|c|}{$\begin{array}{c}\text { PVRI } \\
\text { (Wood units) } \\
\end{array}$} & \multicolumn{2}{|c|}{$\begin{array}{c}\text { PASP } \\
(\mathbf{m m} \mathbf{H g}) \\
\end{array}$} & \multicolumn{2}{|c|}{$\begin{array}{c}\text { PADP } \\
(\mathbf{m m} \mathbf{H g})\end{array}$} & \multicolumn{2}{|c|}{$\begin{array}{l}\text { Qp/Qs } \\
\text { ratio }\end{array}$} & \multirow[b]{2}{*}{ Ao/LA } & \multirow[b]{2}{*}{$\begin{array}{c}\text { Postoperative } \\
\text { course }\end{array}$} & \multirow{2}{*}{$\begin{array}{c}\text { Last } \\
\text { follow-up } \\
(\mathrm{mo}) \\
\end{array}$} & \multirow[b]{2}{*}{$\begin{array}{c}\text { Cardiac } \\
\text { catheterization } \\
\end{array}$} \\
\hline & & & Basal & $\begin{array}{c}\text { After } \\
\mathrm{O}_{2} \\
\end{array}$ & Basal & $\begin{array}{c}\text { After } \\
\mathrm{O}_{2} \\
\end{array}$ & Basal & $\begin{array}{c}\text { After } \\
\mathrm{O}_{2} \\
\end{array}$ & Basal & $\begin{array}{c}\text { After } \\
\mathrm{O}_{2} \\
\end{array}$ & Basal & $\begin{array}{c}\text { After } \\
\mathbf{O}_{2} \\
\end{array}$ & & & & \\
\hline 1 & 5 & F & 91 & 99 & 9.1 & 4.3 & 89 & 60 & 45 & 23 & 1.4 & 3.6 & $21 / 23$ & Uneventful & 56 & Yes \\
\hline 2 & 7 & M & $93^{*}$ & 100 & 16.1 & 9.8 & 102 & 83 & 54 & 31 & 1.1 & 4.5 & $20 / 20$ & Desaturation $\dagger$ & 50 & No \\
\hline 3 & 5 & M & 94 & 98 & 12.6 & 1.8 & 85 & 78 & 46 & 25 & 1.1 & 3.8 & $21 / 24$ & Uneventful & 37 & No \\
\hline 4 & 6 & $\mathrm{~F}$ & 97 & 97 & 10.6 & 2.3 & 92 & 31 & 42 & 12 & 1.7 & 4.9 & $16 / 32$ & Uneventful & 31 & No \\
\hline 5 & 23 & M & 96 & 98 & 13.2 & 4.2 & 110 & 43 & 35 & 35 & 1.8 & 2.9 & $30 / 38$ & Uneventful & 36 & No \\
\hline 6 & 11 & $\mathrm{~F}$ & 96 & 99 & 9.3 & 4.5 & 110 & 46 & 47 & 19 & 1.5 & 3.1 & $25 / 27$ & Uneventful & 49 & Yes \\
\hline 7 & 6 & M & 95 & 98 & 8.7 & 3.2 & 90 & 36 & 34 & 11 & 1.2 & 3.8 & $16 / 20$ & Uneventful & 45 & Yes \\
\hline 8 & 10 & M & $93 *$ & 97 & 13.7 & 4.5 & 76 & 27 & 34 & 12 & 1.7 & 4.3 & $23 / 24$ & Uneventful & 50 & Yes \\
\hline 9 & 13 & $\mathrm{~F}$ & 94 & 99 & 8.9 & 1.9 & 80 & 30 & 23 & 8 & 1.8 & 3.5 & $20 / 27$ & Uneventful & 37 & Yes \\
\hline 10 & 13 & F & 94 & 100 & 13.3 & 2.25 & 102 & 80 & 52 & 34 & 1.16 & 4.2 & $25 / 29$ & Uneventful & 24 & No \\
\hline 11 & 9 & F & 95 & 100 & 8.7 & 2.5 & 104 & 86 & 50 & 40 & 1.3 & 5.4 & $18 / 42$ & Uneventful & 42 & Yes \\
\hline 12 & 2 & M & 94 & 98 & 10.6 & 2.5 & 88 & 67 & 45 & 23 & 1.4 & 2.8 & $18 / 20$ & Uneventful & 22 & No \\
\hline 13 & 2 & M & 89 & 99 & 9.5 & 1.3 & 75 & 65 & 40 & 31 & 1.1 & 3.5 & $19 / 25$ & Desaturation $\dagger$ & 48 & Yes \\
\hline 14 & 5 & $\mathrm{~F}$ & 87 & 98 & 9.4 & 4.2 & 90 & 78 & 66 & 35 & 1.2 & 3.7 & $19 / 28$ & Uneventful & 54 & Yes \\
\hline 15 & 9 & M & 95 & 99 & 11.1 & 5.4 & 110 & 92 & 67 & 36 & 1.1 & 4.5 & $21 / 24$ & Desaturation $\dagger$ & 22 & Yes \\
\hline 16 & 15 & M & 94 & 98 & 9.3 & 4.3 & 103 & 76 & 54 & 27 & 1.4 & 4.1 & $26 / 30$ & Uneventful & 27 & Yes \\
\hline 17 & 15 & M & 91 & 97 & 10.8 & 4.3 & 98 & 66 & 39 & 34 & 1.5 & 3.9 & $22 / 27$ & Uneventful & 8 & No \\
\hline 18 & 7 & $\mathrm{~F}$ & 96 & 100 & 8 & 1.7 & 106 & 104 & 58 & 53 & 2 & 6.5 & $25 / 41$ & Uneventful & 10 & Yes \\
\hline 19 & 5 & $\mathrm{~F}$ & 99 & 100 & 15.1 & 5.1 & 103 & 102 & 62 & 53 & 1.3 & 3.9 & $13 / 20$ & Uneventful & 9 & Yes \\
\hline 20 & 19 & M & 98 & 99 & 9.2 & 5.7 & 115 & 114 & 34 & 34 & 3.2 & 3.9 & $33 / 35$ & Uneventful & 2 & Yes \\
\hline
\end{tabular}

Patients 1, 2, 4, and 7 had an associated atrial septal defect; patients 9, 11, 13, and 17 had an associated patent ductus arteriosus. Pt. No., Patient number; $\mathrm{SpO}_{2}$, oxygen saturation; $P V R I$, indexed pulmonary vascular resistance; $P A S P$, pulmonary arterial systolic pressure; $P A D P$, pulmonary arterial diastolic pressure; $Q p$, pulmonary blood flow; $Q s$, systemic blood flow; $A o$, aorta; $L A$, left atrium; $O_{2}$, oxygen; $F$, female; $M$, male. *Right to left shunt. †Saturation of $<92 \%$ with room air as measured by pulse oximetry.

The electrocardiogram of 4 patients (patients $6,13,16$, and 20) showed right ventricular hypertrophy, and 2 patients (patients 9 and 18) had left ventricular hypertrophy.

On the echocardiogram at the last follow-up examination, no shunt was seen across the UVP through the valve created in it (either left to right or right to left) in any of the patients. One patient had a small left to right residual shunt at the upper margin of the VSD patch. None of the patients had evidence of poor right ventricular function, and, except for 1 patient, all patients had normal left ventricular function. All patients had some degree of insignificant tricuspid regurgitation that was either mild or less than mild. The predicted right ventricular systolic pressure as calculated from the tricuspid regurgitation jet on the echocardiogram was $32.5 \pm 8.6 \mathrm{~mm} \mathrm{Hg}$ (range, 25-45; median, 28). Two patients had mild pulmonary regurgitation.

The electrocardiographic and echocardiographic characteristics of these patients are summarized in Table 2.

\section{Cardiac Catheterization Findings}

Cardiac catheterization data were available for 13 patients who had agreed to undergo cardiac catheterization at the last follow-up visit (Table 3).

For these 13 patients, the mean age was $8.5 \pm 4.4$ years (range, 2-19). The data from 13 patients were not different from the remainder of the cohort who had not agreed to cardiac catheterization. The mean follow-up duration between surgery and cardiac catheterization for these patients was $34.7 \pm 18.6$ months (range, 2-56; median, 42). The mean preoperative systemic saturation for these patients before surgery was $94.1 \% \pm 3.4 \%$, and this had increased to $96.0 \% \pm 2.04 \%$ at the last follow up visit $(P=.13)$.

The mean systolic pulmonary artery pressure (PAP) showed a significant decrease from $96.2 \pm 13.6 \mathrm{~mm} \mathrm{Hg}$ in the preoperative period to $39.6 \pm 11.5 \mathrm{~mm} \mathrm{Hg}$ in the follow-up period $(P=.000)$. A similar and significant decrease in the diastolic PAP was noted from 47.2 \pm 13.8 $\mathrm{mm} \mathrm{Hg}$ to $13.2 \pm 6.9 \mathrm{~mm} \mathrm{Hg}(P=.000)$. The mean PAP also showed a significant decline in the follow-up period, from $51.0 \pm 12.9 \mathrm{~mm} \mathrm{Hg}$ to $24.5 \pm 8.5 \mathrm{~mm} \mathrm{Hg}$ $(P=.000)$. None of the 13 patients had an increase in the mean, systolic, or diastolic PAP. When classifying the patients according to the mean PAP, $4(30.8 \%)$ had no PAH (mean PAP, $12-20 \mathrm{~mm} \mathrm{Hg}$ ), $6(46.2 \%)$ had mild PAH (mean PAP, 21 to $29 \mathrm{~mm} \mathrm{Hg}$ ), and $3(23.1 \%$ ) had moderate PAH (mean PAP, $30-49 \mathrm{~mm} \mathrm{Hg}$ ). None of the patients had severe PAH (mean PAP, $\geq 50 \mathrm{~mm} \mathrm{Hg}$ ). This was in contrast to preoperatively, when all 13 patients had severe PAH (mean PAP, $\geq 50 \mathrm{~mm} \mathrm{Hg}$ ).

The mean $\mathrm{Qp} / \mathrm{Qs}$ ratio for these patients was $1.5 \pm 0.6$ (range, 1.1-3.2) before surgery. At the follow-up point, except for patient 19, who had an increase in the Qp/Qs ratio, all patients had had a decrease in the $\mathrm{Qp} / \mathrm{Qs}$ ratio $(P=.14)$. 
TABLE 2. Echocardiographic and electrocardiographic characteristics of patients who agreed to cardiac catheterization

\begin{tabular}{|c|c|c|c|c|c|c|c|c|}
\hline Pt. No. & $\begin{array}{c}\text { TR gradient } \\
(\mathrm{mm} \mathbf{H g})\end{array}$ & Predicted RVSP & Pulmonary valve & Ao/LA & Shunt & RV function & LV function & ECG findings \\
\hline 1 & 26 & 43 & No PR & $21 / 28$ & No shunt & Normal & Normal & Normal \\
\hline 6 & 30 & 38 & No PR & $27 / 25$ & No shunt & Normal & Normal & RVH \\
\hline 7 & 20 & 27 & No PR & $22 / 25$ & No shunt & Normal & Normal & Normal \\
\hline 8 & 18 & 25 & No PR & $24 / 24$ & No Shunt & Normal & Normal & Normal \\
\hline 9 & 20 & 25 & No PR & $22 / 24$ & No shunt & Normal & Normal & LVH \\
\hline 11 & 21 & 26 & No PR & $20 / 36$ & No Shunt & Normal & Normal & Normal \\
\hline 13 & 20 & 25 & Mild PR & $24 / 24$ & No shunt & Normal & Normal & RVH \\
\hline 14 & 34 & 38 & Mild PR & $20 / 22$ & No shunt & Normal & Normal & Normal \\
\hline 15 & 18 & 28 & No PR & $17 / 18$ & No shunt & Normal & Normal & Normal \\
\hline 16 & 40 & 45 & No PR & $20 / 22$ & No shunt & Normal & Normal & RVH \\
\hline 18 & 20 & 28 & No PR & $26 / 33$ & No shunt & Normal & Normal & LVH \\
\hline 19 & 20 & 26 & No PR & $17 / 24$ & No shunt & Normal & Normal & Normal \\
\hline 20 & 42 & 48 & No PR & $25 / 39$ & $\begin{array}{l}\text { No shunt through patch; } \\
\text { residual shunt at upper end }\end{array}$ & Normal & Mild dysfunction & RVH \\
\hline
\end{tabular}

Pt. No., Patient number; $T R$, tricuspid regurgitation; $R V S P$, right ventricular systolic pressure; $A o$, aorta; $L A$, left atrium; $R V$, right ventricular; $L V$, left ventricular; $E C G$, electrocardiographic; $P R$, pulmonary regurgitation; $R V H$, right ventricular hypertrophy.

The mean PVRI at rest for these 13 patients in the preoperative period was $10.0 \pm 2.1$ Wood units (range, 8.0-15.1; median, 9.3). During follow-up, the PVRI showed a decline in 12 patients $(92.3 \%)$ and an increase in 1 . The mean PVRI at rest for the patients at follow-up was $5.8 \pm 0.6$ Wood units $(P=.02)$. Thus, closure of the VSD with a UVP was associated with a significant decrease in the PVRI $(P=.02$.$) . Of the 13$ patients, at follow-up, $11(84.6 \%)$ had a PVRI of $<8$ Wood units, and only 2 patients $(15.4 \%)$ continued to have a PVRI of $>8$ Wood units (Figure 1). Of these 2 patients with a continued PVRI at rest $>8$ Wood units, 1 had a decrease in the PVRI from 9.3 to 8.3 Wood units, and 1 had a small increase from the preoperative PVRI of 8 Wood units to 8.2 Wood units. The trend of the PVRI for all 13 patients is shown in
Figure 1, and the hemodynamic profile is depicted in Figure 2.

\section{DISCUSSION}

In patients diagnosed with VSD and PAH, the outcomes of VSD closure will be dependent on the Heath-Edwards classification of the changes at closure of such defects. ${ }^{1}$ The morbidity and mortality of VSD closure in such patients with PAH has remained high. ${ }^{2,6}$ Acute pulmonary hypertensive crisis, right ventricular failure, and respiratory failure have been the most common causes of postoperative mortality in such patients. In the study by Moller and colleagues, ${ }^{10}$ an elevated PVR $>7$ Wood units and age $>5$ years were important risk factors for death during long-term follow-up at 30 years. Closure of defects in

TABLE 3. Postoperative characteristics of patients undergoing cardiac catheterization

\begin{tabular}{|c|c|c|c|c|c|c|c|c|c|c|c|c|c|c|c|c|}
\hline \multirow[b]{2}{*}{ Pt. No. } & \multirow[b]{2}{*}{ Age (y) } & \multirow{2}{*}{$\begin{array}{c}\text { Follow-up } \\
\text { (mo) }\end{array}$} & \multicolumn{2}{|c|}{$\begin{array}{c}\text { Basal } \\
\mathrm{SpO}_{2}(\%)\end{array}$} & \multicolumn{2}{|c|}{$\begin{array}{c}\mathrm{SpO}_{2} \text { with } \\
\mathrm{O}_{2}(\%) \\
\end{array}$} & \multicolumn{2}{|c|}{$\begin{array}{c}\text { PASP } \\
(\mathbf{m m ~ H g}) \\
\end{array}$} & \multicolumn{2}{|c|}{$\begin{array}{c}\text { PADP } \\
(\mathbf{m m ~ H g}) \\
\end{array}$} & \multicolumn{2}{|c|}{$\begin{array}{c}\text { Mean PAP } \\
(\mathrm{mm} \mathrm{Hg})\end{array}$} & \multicolumn{2}{|c|}{$\begin{array}{c}\text { Qp/Qs } \\
\text { ratio }\end{array}$} & \multicolumn{2}{|c|}{$\begin{array}{c}\text { PVRI at } \\
\text { rest }\end{array}$} \\
\hline & & & Pre & Post & Pre & Post & Pre & Post & Pre & Post & Pre & Post & Pre & Post & Pre & Post \\
\hline 1 & 5 & 56 & 91 & 96 & 99 & 100 & 89 & 40 & 45 & 10 & 32 & 24 & 1.4 & 1.2 & 9.1 & 6.4 \\
\hline 6 & 11 & 49 & 96 & 97 & 99 & 100 & 110 & 47 & 47 & 21 & 70 & 33 & 1.5 & 0.9 & 9.3 & 8.3 \\
\hline 7 & 6 & 45 & 95 & 96 & 98 & 99 & 90 & 48 & 34 & 10 & 56 & 24 & 1.2 & 0.9 & 8.7 & 7.7 \\
\hline 8 & 10 & 50 & 93 & 93 & 97 & 99 & 76 & 23 & 34 & 8 & 46 & 12 & 1.7 & 0.7 & 13.7 & 1.6 \\
\hline 9 & 13 & 37 & 94 & 95 & 99 & 100 & 80 & 37 & 23 & 13 & 40 & 19 & 1.8 & 0.9 & 8.9 & 6.5 \\
\hline 11 & 9 & 42 & 95 & 98 & 100 & 100 & 104 & 39 & 50 & 5 & 50 & 22 & 1.3 & 1 & 8.7 & 3.2 \\
\hline 13 & 2 & 48 & 89 & 99 & 99 & 99 & 75 & 30 & 40 & 7 & 32 & 23 & 1.1 & 0.9 & 9.5 & 6.1 \\
\hline 14 & 5 & 54 & 87 & 97 & 98 & 100 & 90 & 35 & 66 & 10 & 51 & 19 & 1.2 & 1 & 9.4 & 4 \\
\hline 15 & 9 & 22 & 95 & 92 & 99 & 100 & 103 & 32 & 54 & 11 & 46 & 24 & 1.4 & 0.9 & 9.3 & 5.6 \\
\hline 16 & 9 & 27 & 95 & 97 & 99 & 100 & 110 & 35 & 67 & 10 & 51 & 19 & 1.1 & 0.9 & 11.1 & 6.4 \\
\hline 18 & 7 & 10 & 96 & 96 & 100 & 99 & 106 & 50 & 58 & 22 & 75 & 33 & 2 & 0.8 & 8 & 8.2 \\
\hline 19 & 5 & 9 & 99 & 98 & 100 & 99 & 103 & 31 & 62 & 15 & 50 & 21 & 1.3 & 3.2 & 15.1 & 3.7 \\
\hline 20 & 19 & 2 & 98 & 94 & 99 & 97 & 115 & 68 & 34 & 29 & 64 & 46 & 3.2 & 1.8 & 9.2 & 7.4 \\
\hline
\end{tabular}

Pt. No., Patient number; $\mathrm{SpO}_{2}$, oxygen saturation; $P A S P$, pulmonary artery systolic pressure; $P A D P$, pulmonary artery diastolic pressure; $P A P$, pulmonary artery pressure; $Q p$, pulmonary blood flow; $Q s$, systemic blood flow; PVRI, indexed pulmonary vascular resistance; Pre, preoperative; Post, postoperative. 


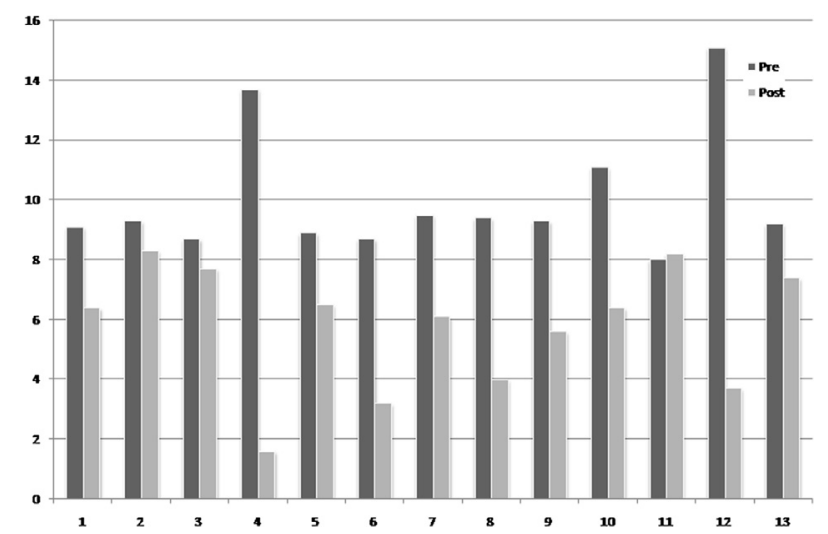

FIGURE 1. Pulmonary vascular resistance index trend in 13 patients undergoing cardiac catheterization 2 to 56 months after closure of the ventricular septal defect using the unidirectional valved patch.

patients in whom the PVRI is $>8$ Wood units has been a debated issue, and patients with fixed PVR have been considered unfit for surgery. However, for those children in whom the PVR is elevated preoperatively, but reactive, surgical closure has been reported by Castaneda and colleague $^{2}$ and Kanan and colleagues. ${ }^{11}$ With the advent of newer pharmacologic and mechanical adjuncts such as phosphodiesterase inhibitors, inhaled nitric oxide, and extracorporeal membrane oxygenation, the postoperative treatment of such patients has become simpler. Experience with high-dose calcium channel blockers ${ }^{12}$ and phosphodiesterase inhibitors and prostacyclins ${ }^{13}$ in the successful treatment of patients with primary pulmonary hypertension has suggested that in younger children, pulmonary vascular remodeling could still be a realistic goal. This, along with

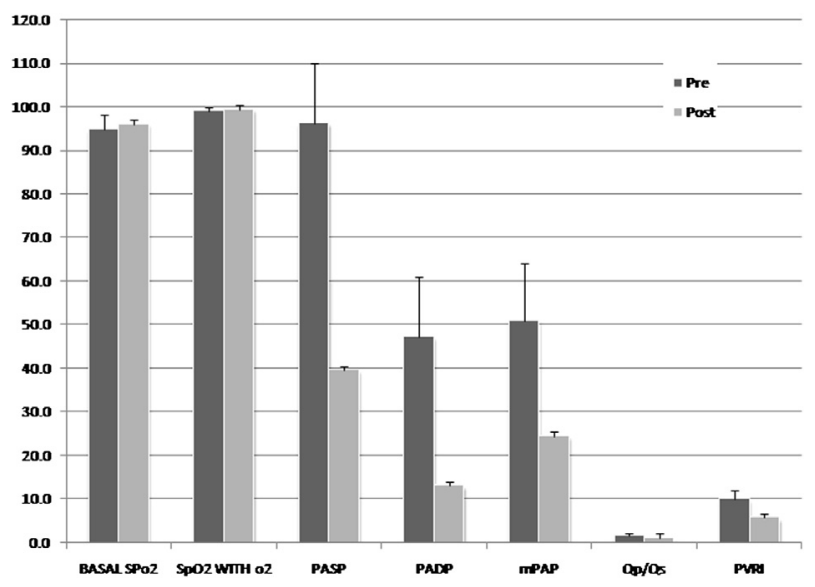

FIGURE 2. Cardiac catheterization data from 13 patients with ventricular septal defect and high pulmonary vascular resistance index (PVRI) 2 to 56 months after closure of ventricular septal defect with unidirectional valved patch. $\mathrm{SpO}_{2}$, Oxygen saturation; $\mathrm{O}_{2}$, oxygen; $P A S P$, pulmonary arterial systolic pressure; $P A D P$, pulmonary arterial diastolic pressure; $I P A P$, mean pulmonary artery pressure; $Q p / Q s$, pulmonary blood flow/systemic blood flow (ratio). previous reports of promising early and intermediate-term results with closure of the VSD with a UVP, make it a promising option in the treatment of patients with an elevated PVRI.

Simple closure of the VSD in such patients has been shown to be associated with mortality rates of $13 \%$ to $24 \% .{ }^{11,14}$ However, using a fenestrated valved patch, Novick and colleagues ${ }^{3,4}$ reported an early mortality of only $3.6 \%$, and using our own technique that we reported earlier, ${ }^{5}$ we did not observe any deaths in our experience, indicating the benefits of this technique. Moreover, just as in the experience of Novick et $\mathrm{al}^{3,4}$ using the UVP, we were able to minimize the duration of mechanical ventilatory support that would otherwise be required in these patients to prevent a pulmonary hypertensive crisis. Other surgical strategies that have been used with mixed results in this subset of patients have been previous pulmonary arterial banding, fenestrated patch closure of the VSD, and leaving an interatrial communication. All these techniques have their inherent limitations. ${ }^{9}$ A UVP, which was first described by Zhou and colleagues ${ }^{8}$ and later modified by Novick and colleagues ${ }^{3,4}$ and Zhang and colleagues, ${ }^{8}$ has been a useful technique in the treatment of such patients. Although reports of the early and intermediate-term results of this technique widely discussed the clinical and echocardiographic profile of these patients, ${ }^{3-5,9}$ the published data regarding the hemodynamic and oximetry outcomes of this technique have been sparse. Of particular interest was the comparison of the results of the UVP with the results with fenestrated closure of VSD. Although fenestrated closure of the VSD has been shown to reduce the early morbidity and mortality in the setting of acute postoperative right ventricular decompensation, it carries a small, but definite, risk of a left to right shunt in the follow-up period should the PAPs decline substantially. This would obviously necessitate reoperation or interventional device closure of the fenestration, ${ }^{15}$ with the potential to significantly increase the costs of care. However, with a UVP, once the PAPs have normalized, the valve simply closes.

In our study, the average decrease in the PVRI was $42 \%$ at the last follow-up visit. The decrease in the PVRI was greater in patients with a greater preoperative PVRI. Of the 2 patients, 1, who still had a PVRI $>8$ Wood units, also had an increase in PVRI from a preoperative value of 8.0 to 8.2 ; however, postoperative interval was only 10 months. The other patient with a high PVRI had no clinical or echocardiographic evidence of right ventricular dysfunction. These data are objective evidence of the success of the UVP technique for closure of the VSD associated with PAH and a high PVRI.

The results of our study would seem to suggest that because the reduction in the PAPs and the right ventricular 
pressures were significant in these patients, their survival should not be different than those patients without significant $\mathrm{PAH}$; however, this remains a hypothesis and cannot be inferred from the results of the present study. It is not known whether the changes that would presumably have occurred in the pulmonary vascular bed would be entirely reversible, even after closure of the defects at this level of PVRI; hence, the need for randomized studies with preand postoperative analysis and exercise testing. Also, the PAPs had decreased but had not yet normalized in several of our patients; thus, close observation is necessary in the long term. It is well known that closure of a VSD in inoperable patients can also result in an initial decrease in the PAP to lower than the preoperative values but increases over time. ${ }^{14}$ Therefore, a larger randomized study with cardiac catheterization data and pre- and postoperative analysis with exercise testing would be required to comment on this issue.

\section{Study Limitations}

A major limitation of our study was that the numbers were small, and the follow-up period was short. None of our patients had obvious Eisenmenger syndrome. No exercise testing was used, and the response to other pulmonary vasodilators was not noted. We did not perform lung biopsy for any of our patients. Finally, the applicability of this technique to patients who are clearly inoperable or have Eisenmenger syndrome is not known.

\section{CONCLUSIONS}

The results of our study have shown that in patients with borderline operability, UVP closure is a viable technique with promising immediate, early, and midterm results and a favorable effect on the hemodynamic and oximetry parameters. For patients with established Eisenmenger syndrome, additional evaluation is required to comment on the utility of UVP closure of VSDs.

\section{References}

1. Rabinovitch M, Keane JF, Norwood WI, Castaneda AR, Reid L. Vascular structure in lung tissue obtained at biopsy correlated with pulmonary hemodynamic findings after repair of congenital heart defects. Circulation. 1984;69:655-67.

2. Castaneda AR, Zamora R, Nicoloff DM, Moller JH, Hunt CE, Lucas RV. Highpressure, high-resistance ventricular septal defect. Ann Thorac Surg. 1971;12: 29-38.

3. Novick WM, Gurbuz T, Watson DC, Lazorishinets VV, Perepeka AN, Malcic I, et al. Double patch closure of ventricular septal defect with increased pulmonary vascular resistance. Ann Thorac Surg. 1998;66:1533-8.

4. Novick WM, Sandoval N, Lazorhysynets VV, Castillo V, Baskevitch A, Mo X, et al. Flap valve double patch closure of ventricular septal defects in children with increased pulmonary vascular resistance. Ann Thorac Surg. 2005;79:21-8.

5. Choudhary SK, Talwar S, Airan B. A simple technique of unidirectional valved patch for closure of septal defects. J Thorac Cardiovasc Surg. 2007;134:1357-8.

6. Talwar S, Choudhary SK, Airan B, Saxena A, Kothari SS, Juneja R. Unidirectional valved patch for closure of septal defects in patients with severe pulmonary hypertension. Ann Pediatr Cardiol. 2008;1:114-9.

7. Zhou Q, Lai Y, Wei H, Song R, Wu Y, Zhang H. Unidirectional valve patch for repair of cardiac septal defects with pulmonary hypertension. Ann Thorac Surg. 1995;60:1245-8.

8. Zhang B, Wu S, Liang J, Zhang G, Jiang G, Zhou M, et al. Unidirectional monovalve homologous aortic patch for repair of ventricular septal defect with pulmonary hypertension. Ann Thorac Surg. 2007;83:2176-81.

9. Talwar S, Choudhary SK, Garg S, Saxena A, Ramakrishna S, Kothari SS, et al. Unidirectional valved patch closure of ventricular septal defects with severe pulmonary arterial hypertension. Interact Cardiovasc Thorac Surg. 2012;14 699-702.

10. Moller JH, Patton C, Varco RL, Lillehei CW. Late results (30 to 35 years) after operative closure of isolated ventricular septal defect from 1954 to 1960. Am J Cardiol. 1991;68:1491-7.

11. Kanan BR, Sivasankaran S, Thakaran JA, Titus T, Ajith Kumar VK, Francis B, et al. Long-term outcome of patients operated for large ventricular septal defects with increased pulmonary vascular resistance. Indian Heart J. 2003;55:161-6.

12. Rich S, Kaufmann E, Levy PS. The effect of high doses of calcium channe blockers on survival in primary pulmonary hypertension. N Engl J Med. 1992 327:76-81.

13. Barst RJ, Rubin LJ, Long WA, McGoon MD, Rich S, Badesch DB, et al. A comparison of continuous intravenous epoprostenol (prostacyclin) with conventional therapy for primary pulmonary hypertension. $N$ Engl J Med. 1996;334:296-301.

14. Hallidie Smith KA, Hollman A, Cleland WP, Bentall HH, Goodwin JF. Effects of surgical closure of ventricular septal defects upon pulmonary vascular disease. $\mathrm{Br}$ Heart J. 1969;31:246-60.

15. Lei BF, Chen JM, Cen JZ, Lui RC, Ding YQ, Xu G, Zhuang J. Palliative arterial switch for transposition of the great arteries, ventricular septal defect, and pulmonary vascular obstructive disease: midterm outcomes. J Thorac Cardiovasc Surg. 2010;140:845-9. 